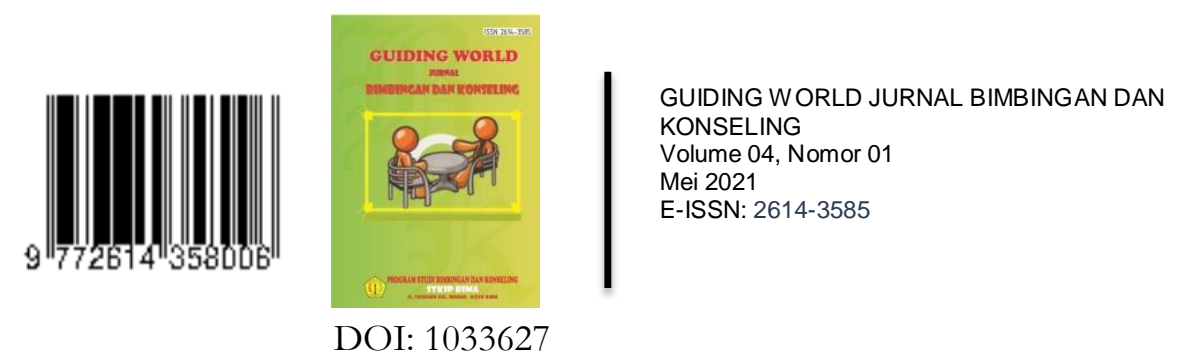

\title{
Penerapan Metode Small Group Discussion untuk Meningkatkan Keaktifan Mahasiswa Bimbingan dan konseling STKIP Bima
}

\section{The Application of the Small Group Discussion method to increase the activeness of student guidance and counseling STKIP Bima}

\author{
Ulfatul Mutahidah, Muhamadiah* \\ Sekolah Tinggi Keguruan Dan Ilmu Pendidikan (STKIP) Bima \\ Email:muhamadiah_bk@stkipbima.ac.id
}

\begin{abstract}
Abstrak: $\quad$ Penelitian ini bertujuan untuk menerapkan small grup discussion untuk meningkatkan keaktifan mahasiswa Bimbingan dan Konseling pada mata kuliah konseling lintas budaya. Keaktifan dalam penelitian ini yaitu keaktifan dalam bertanya, menjawab pertanyaan, berdiskusi dan presentasi, serta menyampaikan refleksi diri. Metode yang digunakan dalam penelitian ini adalah metode kualitatif. Metode ini bersifat deskriptif, menggunakan analisis, mengacu pada data, dan memanfaatkan teori yang ada sebagai bahan pendukung. Peneliti melakukan analisis dengan pengamatan proses edukasi dan melakukan wawancara dengan mahasiswa Bimbingan dan Konseling STKIP Bima, untuk mendapatkan informasi terkait keefektifan metode Small Group Discussion. Sementara pendekatan penelitian menggunakan deskriptif kualitatif. Dalam penelitian ini populasi terdiri dari seluruh mahasiswa Kelas A semester 2 Bimbingan dan Konseling di STKIP Bima yang berjumlah 32 siswa.Teknik pengumpulan data yaitu observasi dan wawancara. Berdasarkan deskripsi data yang telah penulis paparkan dari data - data obsrvasi dan wawancara dengam mahasiswa bimbingan dan konseling stkip bima, dapat dianalisis bahwa metode Small group discussion dapat menumbuhkan pemahaman mahasiswa tentang materi yang terdapat dalam mata kuliah konseling lintas budaya tersebut dengan tujuan mahasiswa mampu memecahkan masalah dengan berkelompok secara demokratis, sehingga mempunyai kecakapan yang sesuai dengan kebutuhan yaitu mengenai pemahaman materi perkuliahan dan dapat mengamalkannya dalam kehidupan sehari-hari. Selain itu mahasiswa dapat bertukar pikiran dengan teman sekelompoknya dan adanya saling menghargai satu sama lain dalam memberikan suatu pendapat mengenai persoalan atau permasalahan yang ada.
\end{abstract}


Kata Kunci : Small Group Discussion, Keaktifan Mahasiswa, Konseling Lintas Budaya

Abstract: This study aims to implement a small group discussion to increase the activeness of Guidance and Counseling students in the crosscultural counseling course. Activeness in this research is activeness in asking questions, answering questions, discussing and presenting, and conveying self-reflection. The method used in this research is qualitative method. This method is descriptive, uses analysis, refers to data, and uses existing theories as supporting material. The researcher conducted an analysis by observing the educational process and conducting interviews with the students of Guidance and Counseling STKIP Bima, to obtain information related to the effectiveness of the Small Group Discussion method. While the research approach used a qualitative descriptive. In this study the population consisted of all Class $A$ students in semester 2 of Guidance and Counseling at STKIP Bima, totaling 32 students. Data collection techniques were observation and interviews. Based on the description of the data that the author has described from observational data and interviews with STKIP Bima guidance and counseling students, it can be analyzed that the Small group discussion method can foster students' understanding of the material contained in the cross-cultural counseling course with the aim of students being able to solve problems. with groups in a democratic manner, so that they have skills that are in accordance with the needs, namely regarding the understanding of lecture materials and being able to practice them in everyday life. In addition, students can exchange ideas with their group of friends and have mutual respect for each other in giving an opinion about the problem or problem that exists.

Keywords: Small Group Discussion, Student Activity, Cross Cultural Counseling 


\section{PENDAHULUAN}

Secara konvensional, pembelajaran mahasiswa sarjana dilaksanakan melalui perkuliahan didaktik, praktikum, tutorial, dan klinik. Hal tersebut terlihat masih menggunakan metode mengajar yang pasif, sehingga mahasiswa minim dalam pemecahan masalah atau keterampilan penalaran, dan hampir tidak ditemukan keaktifan dalam proses pembelajaran (Gade \& Chari , 2013). Hanya dosen tertentu yang mampu menarik perhatian mahasiswa dari awal sampai akhir kuliah (Aryani \& Supriyadi, 2018).

Perkembangan zaman melek iptek saat ini, dimana mahasiswa sangat kritis dalam menyampaikan sesuatu hal. Sangat dibutuhkan metode mengajar yang dapat membuat mahasiswa menjadi aktif dan kreatif dalam berpikir dan berinovasi. Itu sebabnya mahasiswa perlu dipersiapkan untuk menghadapi tantangan dan perjuangan ke depan, Afandi, et al dalam (Usmani, 2019) .

Hasil observasi ternyata motivasi belajar mahasiswa kurang karena masih menggunakan metode pembelajaran ceramah sehingga mahasiswa merasa bosan, jenuh dan hanya dosen yang berperan aktif, sedangkan mahasiswa hanya mendengar dan menulis apa yang disampaikan oleh dosennya. Salah satu teknik mengoptimalkan pontesi mahasiswa dengan melibatkanya secara aktif dalam proses pembelajaran ( Ahmad \& Nurma, 2020). Keaktifan merupakan point penting dalam mendorong untuk melakukan berbagai aktivitas pembelajaran sehingga dapat menumbuhkan dan memperkuatkan pemahaman tentang bimbingan dan konseling.

Pada awal perkuliahan dosen menggunakan metode ceramah dengan teknik presentasi agar mahasiswa menjadi aktif, ternyata hanya sedikit yang aktif. Dosen mencoba mengganti metode dalam perkuliahan untuk mengaktifkan mahasiswa yaitu dengan menerapkan small group discussion atau diskusi pada kelompok kecil. Salah satu metode pengajaran yang diminati mahasiswa yaitu metode pembelajaran small group discussion (SGD) karena melibatkan antara kelompok mahasiswa dan pengajar untuk menganalisa, menggali atau memperdebatkan topik atau permasalahan tertentu (Gantino, Ruswanti, \& Taufiqurrahman, 2020).

Menurut Kindsvatter (1996: 242), Small group discussion adalah sekelompok kecil siswa untuk mencapai tujuan tertentu yang memungkinkan siswa untuk lebih bertanggung jawab atas pembelajaran mereka sendiri, mengembangkan keterampilan sosial dan kepemimpinan dan terlibat dalam pendekatan instruksional alternative (Bohari, 2019). small group discussion membantu mahasiswa untuk mengembangkan keterampilan komunikasi dan dengan antusias mengasah pengetahuan melalui diskusi yang dinamis dan bersemangat melalui berbagai sudut pandang (Thotakura \& Anuradha, 2018).

Hasil penelitian oleh (Rahmawati \& Elsanti, 2020) bahwa metode small group discussion efektif terhadap tingkat pengetahuan remaja tentang kesehatan reproduksi sebelum dan sesudah dilakukan pendidikan kesehatan. Hasil lainya mengungkapkan bahwa ada pengaruh penggunaan metode pembelajaran terhadap nilai hasil belajar (Gantino, Ruswanti, \& Taufiqurrahman, 2020). Hal tersebut diperkuat, dengan hasil penelitian menggunakan metode active learning dengan diskusi kelompok atau small group discussion dapat meningkatkan keaktifan belajar yang melibatkan mahasiswa semester 4 kelas D mata kuliah perkembangan peserta didik jurusan PAI FIAI UII Yogyakarta yang ditinjau dari teoriteori yang dikemukakan oleh para ahli (Syamsiyati N.J, 2019). Lebih lanjut, metode SGD dapat meningkatkan hasil belajar dan keaktifan mahasiswa (Purwanti, 2017). Berdasarkan 
penelitian tersebut, membuktikan bahwa metode SGD dapat memberikan hasil positif terhadap proses dan hasil belajar pada mahasiswa.

\section{METODE PENELITIAN}

Metode yang digunakan dalam penelitian ini adalah metode kualitatif. Metode ini bersifat deskriptif, menggunakan analisis, mengacu pada data, dan memanfaatkan teori yang ada sebagai bahan pendukung. Peneliti melakukan analisis dengan pengamatan proses edukasi dan melakukan wawancara dengan mahasiswa Bimbingan dan Konseling STKIP Bima, untuk mendapatkan informasi terkait keefektifan metode Small Group Discussion. Sementara pendekatan penelitian menggunakan deskriptif kualitatif. Dalam penelitian ini populasi terdiri dari seluruh mahasiswa Kelas A semester 2 di STKIP Bima yang berjumlah 32 siswa. Sampel di sini sebagian dari populasi yang dipilih oleh peneliti sebagai wakil dari populasi yang representatif yang dijadikan subyek dalam penelitian untuk memudahkan peneliti untuk mendapatkan dan mengumpulkan data di lokasi penelitian. Populasi berjumlah 32 dapat diambil 28 dari taraf signifikan 5\%. Sampel yang digunakan dalam penelitian ini adalah sebanyak 1 (kelas) yang ditentukan, peneliti menetapkan kelas A semester 2 dan sebagai sampel penelitian yang dipilih dengan teknik simple random sampling. Jadi sampel yang digunakan adalah 28 orang mahasiswa. Selanjutnya peneliti membuat undian untuk mendapatkan sampel pertama. Setelah mendapatkan sample pertama, maka nomor yang terpilih dikembalikan lagi agar populasi tetap utuh sehingga sample berikutnya tetap sama dengan sampel pertama, langka tersebut kembali dilakukan hingga jumlah sampel memenuhi kebutuhan penelitian (Anshori \& Iswati, 2009). Teknik pengumpulan data yaitu dengan observasi untuk mendapatkan data bahwa mahasiswa membutuhkan metode pengajaran Small group discussion untuk meningkatkan keaktifan mahasiswa didalam kelas dan wawancara untuk mendapatkan data bahwa metode small group discussion efektif untuk meningkatkan keaktifan mahasiswa. Dalam menganalisis data penulis menggunakan metode deskriptif kualitatif, yaitu data yang diperoleh digambarkan dengan kata-kata atau kalimat menurut masing-masing kategori untuk penarikan kesimpulan Untuk menganalisis data ini penulis menggunakan analis deduktif. Analisis ini cara kerjanya adalah dilihat dari teori kemudian dikaitkan dengan fakta dan kenyataan yang ada di lapangan (Syamsiyati N.J, 2019).

\section{DEFINISI OPERASIONAL VARIABEL}

\section{Small Group Discussion (SGD)}

Pembelajaran dengan metode Small Group Discussion adalah serangkaian

kegiatan belajar yang dilakukan oleh peserta didik dalam kelompok-kelompok tertentu untuk mencapai tujuan pembelajaran yang telah ditentukan. Ada empat unsur penting dalam pembelajaran Small Group Discussion: 1. Adanya peserta, 2. adanya aturan, 3. upaya belajar setiap kelompok dan, 4. Tujuan yang akan dicapai . Ismail dalam (Taufik, 2019). Metode SGD dimulai dengan dosen menyajikan permasalahan secara umum, kemudian masalah tersebut dibagi per sub bab yang harus dipecahkan setiap kelompokkelompok kecil, setelah selesai diskusi, perwakilan dari tiap kelompok menyajikan hasil diskusinya masing-masing. .tujuan dari sgd yaitu mahasiswa bisa saling memecahkan masalah-masalah yang terjadi di lingkungan sekitar mereka, baik dalam kehidupan seharihari maupun permasalahan yang terjadi di dalam kelas, Mahasiswa dapat berdiskusi dan 
saling mengoreksi satu sama lain mengenai pemahaman mereka dalam proses pembelajaran di kelas, sehingga mahasiswa bisa memahami dengan lebih baik (Sulistyowati, 2016).

2. Keaktifan Mahasiswa

Keaktifan dalam belajar merupakan permasalahan yang mendasar dan urgen yang harus dipahami, disadari dan dikembangkan oleh setiap tenaga pendidik dalam proses belajar. Keaktifan dalam belajar ditandai dengan adanya keterlibatan yang aktif dari segi intelektual, emosi dan fisik, Aunurrahman dalam ( Astuti, 2017). Dalam proses pembelajaran di bangku perkuliahan hendaknya mahasiswa dapat lebih bersifat aktif sehingga dapat mengurangi dominasi dosen saat pelaksanaan proses belajar mengajar dikelas. Keaktifan mahasiswa juga dapat digunakan untuk mengecek pemahaman terhadap materi kuliah yang diberikan.

\section{HASIL DAN PEMBAHASAN}

Berdasarkan deskripsi data yang telah penulis paparkan dari data - data obsrvasi dan wawancara dengam mahasiswa bimbingan dan konseling stkip bima, dapat dianalisis bahwa metode Small group discussion dapat menumbuhkan pemahaman mahasiswa tentang materi yang terdapat dalam mata kuliah konseling lintas budaya tersebut dengan tujuan mahasiswa mampu memecahkan masalah dengan berkelompok secara demokratis, sehingga mempunyai kecakapan yang sesuai dengan kebutuhan yaitu mengenai pemahaman materi perkuliahan dan dapat mengamalkannya dalam kehidupan sehari-hari. Selain itu mahasiswa dapat bertukar pikiran dengan teman sekelompoknya dan adanya saling menghargai satu sama lain dalam memberikan suatu pendapat mengenai persoalan atau permasalahan yang ada.

Dari proses pelaksaaan pembelajaran metode Small group discussion, terlihat mahasiswa sangat antusias karena biasanya dosen memberikan materi dengan persentasi metode ceramah, dan sekarang memberikan materi dengan berkelompok. Dosen mengarahkan untuk membuat 5 kelompok, dengan satu kelompok ada yang berjumlah 6 dan 7 orang. Cara pembentukan kelompok yaitu mahasiswa berhitung 1 sampai 6 . Hal tersebut dilakukan agar mahasiswa dapat berbaur dengan sesama teman di kelasnya dan tidak boleh untuk manganti anggota kelompoknya. Dosen mengarahkan mahasiswa untuk memilih siapa ketua kelompok, sekretaris, dan anggota kelompok. Setiap kelompok membaca materi yang telah diberikan, merangkum, menuliskan point-point penting berdasarkan hasil diskusi setiap kelompok, dan mempersentasikanya di depan kelas. Setiap mahasiswa harus berani berbicara saat persentasi, sehingga setiap mahasiswa memiliki kesempatan yang sama untuk menyampaikan persentasinya berdasarkan hasil dsikusi.

Peningkatan pemahaman mahasiswa terkait materi, dosen menggunakan metode yang dianggap sesuia dan sesuai dengan kebutuhan mahasiswa saat ini. Keaktifan mahasiwa meningkat dan dominan, sehingga pemahaman meningkat sejak dosen menggunakan metode small group discussion. Hal tersebut ditandai dengan keaktifan mahasiswa yang awalnya tidak berani menyampaikan pendapatnya menjadi berani menyampaikan pendapatnya. Mahasiswa dengan tidak sadar dilatih berani untuk berbicara dan mahasiwa lain berlatih untuk mendengarkan pendapat temanya. Selain itu, mahasiswa menjadi lebih peka terhadap temanya yang lain, sehingga secara emosional dan social terbentuk hal 
positif. Terlihat, semangat dan antusias mahasiswa dalam proses pembelajaran. Situasi kelas menjadi aktif dan menyenangkan.

Pada akhir pertemuan dosen melakukan evaluasi dengan memberikan tugas, bersama - sama menarik kesimpulan dari materi yang dibahas saat itu, dan refleksi diri. Refleksi diri mahasiswa terkait perkuliahan dengan metode small group discussion berdasarkan arahan dari dosen. Refleksi terkait pendapat mahasiswa tentang perkuliahan dengan metode yang dilakukan, menarik atau tidak, apa yang perlu ditingkatkan, dan apa hal baru yang didapatkan selama perkuliahan tersebut. Pada awalnya dosen ingin memilih beberapa mahasiswa untuk menyampaikan refleksi diri, tetapi pada faktanya hampir semua mahasiswa ingin menyampikan refleksi diri.

Berdasarkan aktifitas metode small group discussion terlihat bahwa antusias dan keaktifan, serta pengetahuan mahasiswa meningkat, karena mahasiswa yang aktif dalam mencari tahu terkait materi yang disampaikan dosen. Mahasiswa dapat lebih menghargai pendapat temanya, meskipun pendapatnya berbeda. Sikap toleran tersebut yang ingin ditingkatkan juga oleh dosen. Mahasiswa tidak menertawakan saat temanya menyampaikan pendapatnya. Materi yang disampaikan menjadi mudah dipahami dan diingat oleh mahasiswa. Mahasiswa dapat berbagi pendapatnya dan dosen meluruskan apa yag disampaikan mahasiswa.

\section{PENUTUP}

Pembelajaran mata kuliah konseling lintas budaya dengan metode small group discussion berpengaruh terhadap peningkatan keaktifan belajar yang melibatkan mahasiswa semester 2 kelas A jurusan Bimbingan dan Konseling STKIP Bima. Hal tersebut terbukti dengan keterlibatan mahasiswa yang aktif dalam berdiskusi dengan teman yang lain, serta dalam persentasi didepan kelas. Antusias yang tinggi terlihat sehingga suasana kelas menjadi hidup. Mahasiswa dapat lebih menghargai pendapat temanya meskipun pendapatnya berbeda.

Dosen mata kuliah konseling lintas budaya menganggap bahwa metode small group discussion merupakan yang paling cocok diaplikasikan pada mahasiswa untuk belajar secara aktif secara efektif dan efisien, sehingga menjadikan mahasiswa aktif dan dosen hanya memberikan penguatan dan meluruskan jika yang disampaikan mahasiswa tidak sesuai dengan materi perkualihan. Harapan penulis terhadap penulis lainya agar dapat mengembangkan metode small group discussion untuk penelitian yang lain. selain itu, diharapkan pengembangkan small group discussion dalam ranah yang lebih luas lagi. 


\section{DAFTAR PUSTAKA}

Ahmad, K. H., \& Nurma, S. (2020). Penerapan Metode Small Group Discussion Terhadap Motivasi Belajar Siswa. CIVICUS : Pendidikan-Penelitian-Pengabdian Pendidikan Pancasila \& Kewarganegaraan.

Astuti, C. C. (2017). Analisis Korelasi untuk Mengetahui Keeratan Hubungan antara Keaktifan Mahasiswa dengan Hasil Belajar Akhir. Journal of Information and Computer Technology Education.

Anshori, M., \& Iswati, S. (2009). Metodologi Penelitian Kuantitatif. Surabaya Pus. Pnb. dan Percetakan UNAIR.

Aryani, N., \& Supriyadi. (2018). Implementation of small group discussion as a. Journal of Physics: Conference Series.

Bohari, L. (2019). Improving Speaking Skills Through Small Group Discussion At Eleventh Grade Students Of Sma Plus Munirul Arifin Nw Praya. Journal of Languages and Language Teaching.

Gade, S., \& Chari , S. (2013). Pembelajaran berbasis kasus dalam fisiologi endokrin: Pendekatan menuju pembelajaran mandiri dan pengembangan soft skill pada mahasiswa kedokteran. $A d v$ Physiol Educ.

Gantino, R., Ruswanti, E., \& Taufiqurrahman. (2020). Efektifitas Implementasi Metode Ajar Scl Model Small Group Discussion. Jurnal Ekonomi : Journal of Economic.

Purwanti, S. (2017). Penerapan Small Group Discussion Untuk Meningkatkan Hasil Belajar Dan Keaktifan Mahasiswa Pgsd Uad. Jurnal Dialektika Jurusan Pgsd.

Rahmawati, K., \& Elsanti, D. (2020). Efektivitas Metode Ceramah Dan Small Group Discussion Tentang Kesehatan Reproduksi. Jurnal Keperawatan Muhammadiyah.

Sulistyowati, N. (2016). Implementasi Small Group Discussion Dan Collaborative Learning Untuk Meningkatkan Prestasi Belajar Mahasiswa Program Studi Pendidikan Akuntasi IKIP PGRI Madiun. Jurnal Akuntasi dan Pendidikan.

Syamsiyati N.J, E. (2019). Penerapan Metode Pembelajaran "Active Learning-Small Group Discussion" Di Perguruan Tinggi Sebagai Upaya Peningkatan Proses Pembelajaran. Fondatia : Jurnal Pendidikan Dasar. 
Taufik, A. (2019). Pembelajaran Zakat Dengan Multimedia Interaktif Melalui Strategi Paikem Untuk Meningkatkan Hasil Belajar Peserta Didik (Studi Kasus Kelas X.IPA.4 SMAN 1 Karangtengah Demak). El Tarbawi.

Usmani, E. Y. (2019). Analisis Efektivitas Metode Pembelajaran Small Group Discussion Pada Mahasiswa Kedokteran FK UNS. 